\title{
TRANSFORMAÇÕES DO ESPAÇO URBANO NO CERRADO AMAPAENSE: A CIDADE DE MACAPÁ, SANTANA E PORTO GRANDE
}

\author{
Transformations of the urban space in the amapaense cerrado: the cities of Macapá, Santana \\ e Porto Grande
}

\author{
Rosinete Cardoso Ferreira* \\ Adriano Michel Helfenstein** \\ ${ }^{*}$ PPG em Geografia - UFG - rosi cardoso@hotmail.com. \\ **PPG em Geografia - UFG - adriano_amh@hotmail.com.
}

\author{
Recebido em 15/05/2018. Aceito para publicação em 25/06/2018.
}

Versão online publicada em 10/08/2018 (http://seer.ufrgs.br/paraonde)

\begin{abstract}
Resumo: Este trabalho visa demonstrar as transformações ocorridas no espaço urbano das cidades de Macapá, Santana e Porto Grande nos últimos anos. Para tal, nos apoiaremos em imagens que no nosso entender demonstram mudanças na forma e na função que esses espaços vêm adquirindo, fruto das transformações pelas quais passam o cerrado amapaense no período de implementação e consolidação do modelo de produção capitalista do campo chamado de agronegócio, que vai refletir na forma como é pensado e organizado os espaços urbanos citados anteriormente.
\end{abstract}

Palavras-chave: Espaço Urbano; Cerrado Amapaense; Forma e Função.

\begin{abstract}
This paper aims to demonstrate the transformations that occurred in the urban space of the cities of Macapá, Santana and Porto Grande in recent years. To this end, we will rely on images that in our opinion demonstrate changes in the form and function that these spaces have been acquiring, the result of the transformations that the cerrado amapaense undergoes in the period of implementation and consolidation of the model of capitalist production of the field called agribusiness, Which will reflect in the way the urban spaces mentioned above are thought and organized.
\end{abstract}

Key-words: Urban Space; Amapense Cerrado; Form and Function.

\section{Introdução}

No início da ocupação portuguesa a necessidade de conquistar e explorar o território amazônico foi responsável pelo surgimento de várias cidades, como Macapá, capital do Estado do Amapá. Localizada a margem esquerda do rio Amazonas, o surgimento de Macapá é resultado da política de fortificação do governo português no século XVIII, aspecto que difere a Amazônia da lógica da urbanização de outras regiões do Brasil.

O estado do Amapá sofreu um movimento acirrado da política de migração populacional, principalmente na cidade de Macapá, ocorrida a partir da década de 1990 e que acelerou o crescimento demográfico. De cada quatro habitantes três moram na capital, Macapá. Esta, além de concentrar a maior população, é banhada pelo rio Amazonas e cortada pela Linha Imaginária do Equador, o que atribui um caráter simbólico para os moradores da região.

As imagens extremadas historicamente sobre a Amazônia, e o estado do Amapá se insere nessa análise, se reproduzem ainda hoje com novas feições e intensidades, principalmente referentes aos projetos de desenvolvimento que, na região, são polarizados entre exploração mineral e vegetal, em tempos e espaços diferenciados e com aspectos singulares. 
O uso do cerrado amapaense como espaço explorado para fins de produção agrícola é bem recente. Antes, seu uso estava atrelado a silvicultura e pecuária, com reflexo no comércio local e não chegava a ultrapassar a fronteira estadual. Nas últimas décadas do século XX a Amazônia sofre a massiva expansão de áreas de produção de grãos, e a fronteira econômica amapaense vem abrindose nos últimos anos para a convivência com um novo vizinho: os produtores de soja.

O cultivo de grãos no estado do Amapá é bem prematuro, se comparado a outros estados do Brasil, principalmente aos produtores do Centro-Oeste, que desenvolvem essa produção há muitas décadas, formando uma vasta rede de circulação, de infraestrutura e de ocupação de adensamentos urbanos nas capitais desses estados da região. Ao pensar no sintético exemplo relatado, faz-se necessário refletir sobre como está se dando essa transformação no espaço com maior adensamento populacional do estado amapaense: a cidade de Macapá.

Este estudo propõe uma reflexão sobre as transformações do espaço urbano da cidade de Macapá nos últimos quinze anos e analisar o processo de ocupação do cerrado amapaense pelo agronegócio e suas implicações no espaço urbano da cidade de Macapá. Para Lefebvre (2006, p.9), existe uma dificuldade em compreender imediatamente a lógica da transformação no presente, porque é complexa, pois "todo dispositivo espacial repousa sobre a justaposição" e complementa que essas relações que se dão espacialmente não sendo "imediata e imediatamente apreendidas". É percebida falta de consenso e sobram polêmicas e imprecisões quanto a chegada desse modo de produção que se agiganta na região amapaense.

No início da ocupação portuguesa, a necessidade de conquistar e explorar o território amazônico foi responsável pelo surgimento de várias cidades, como Macapá. Os primeiros núcleos populacionais surgiram ao longo das vias fluviais, a partir de fortificações, se tornando importante para a vida econômica local. Juntamente com a política de migração populacional, ocorreu a partir da década de 1990 e um acelerado crescimento demográfico se concentrou em dois maiores adensamentos: Macapá e Santana.

A população amapaense totaliza 782.295 habitantes (IBGE, 2016), na qual 74\% está concentrada entre as cidades de Macapá e Santana, os maiores adensamentos populacionais. A cada 4 habitantes 3 moram na capital, Macapá. Esta, além de concentrar a maior população, é banhada pelo rio Amazonas e cortada pela Linha Imaginária do Equador, o que atribui um caráter simbólico para os moradores da região, ressaltado em poesias e músicas. Para Tavares $(2013$, p.4), “Macapá apresenta-se pouco valorizada no contexto nacional, sendo conhecida apenas como capital do estado do Amapá, fragilizada quanto a presença de estrutura urbana eficiente e de qualidade".

A população urbana, no quesito cor ou raça, 137.074 se declaram brancos, 45.292 pretos, 348.060 pardos e 845 indígenas (IBGE, 2010). Do total de residentes 269.142 não são naturais do Estado, do total de 424.098 pessoas. Os números apresentados justificam o foco sobre o contexto do homem urbano neste trabalho a partir das peculiaridades identitária identificadas na capital Macapá. Nesta, a população ocupa lugares de acordo com a posição econômica e social e não pela cultura, daí é um espaço complexo a ser analisado. Complexidade que Carlos narra, ao afirmar que:

As pessoas passam na rua, umas pelas outras, sem se ver, ninguém parece ser especialmente notado. 0 cidadão parece passar despercebido na multidão de rostos preocupados ou mesmo sem expressão, perdidos no burburinho de vozes e sons indistintos. 0 constante ir e vir das pessoas acontece sem que elas deixem rastros aparentes... (2007, p.75).

É certo que a descrição acima não pode ser aplicada a todas as cidades, os momentos identificados e que marcam um movimento que altera a feição identitária do amapaense é bem similar a retratada por Darcy Ribeiro no filme 0 povo brasileiro, sendo: as matrizes da origem da composição do povo brasileiro, o indígena, negra, colonizador; a dimensão da mistura no território brasileiro, no Amapá ocorreu em meados do século XVIII; o tipo de ambiente, próximos aos rios; e os aspectos da vivencia 
e modo de produção que cada componente assumiu.

A área urbana de Macapá vive a emergência do surgimento de várias identidades, narrativas e territorialidades de diversas populações, principalmente migrantes e negras, uma manifestação da fragmentação cultural.

A camada que interage na cidade se reflete no cotidiano da sociedade amapaense. Esta, impregnada e invadida pela lógica da mercadoria, aspecto que Carlos (2007) evidencia ao afirmar que a condição de cidadania da população é quando transformam o homem em consumidor, e mais, que o espaço se reproduz, ele próprio como mercadoria. Essas afirmações causam estranhamento e deixa um sentimento de não pertencimento, que é um sintoma da modernidade.

O que existe são realidades que se justapõem, é uma perspectiva espacial que não pode ser desvinculada da econômica. Mesmo assim, é difícil simplificadamente compreender, o que Lefebvre (2006) ressalta que essa compreensão dessa dinâmica pela lógica do espaço da "modernidade" contém características especificas para seu entendimento: ser homogêneo-fragmentadohierarquizado. Talvez, o grande desafio seja o de pensar as características identitária amapaense articulado com esse tempo moderno, veloz. Esse pensamento ainda é embrionário.

\section{Produção, organização espacial e fronteira}

Pensar a organização do espaço no contexto atual tem sido a finalidade de muitos estudiosos, geógrafos ou não. Essa tarefa a princípio coloca os pesquisadores diante de um mundo no qual,

A aceleração contemporânea impôs novos ritmos ao deslocamento dos corpos e ao transporte das ideias, mas, também, acrescentou novos itens à história. Junto com uma nova evolução das potências e dos rendimentos, com o uso de novos materiais e de novas formas de energia, o domínio mais completo do espectro eletromagnético, a expansão demográfica (a população mundial triplica entre 1650 e 1900, e triplica de novo entre 1900 e 1984), a explosão urbana e a explosão do consumo, o crescimento exponencial do número de objetos e do arsenal de palavras (SANTOS, 1994, p. 12).

Diante dessa complexidade que interfere na forma como o mundo é organizado, a nós profissionais ligados a Geografia, nos interessa compreendê-lo sob o prisma de uma linguagem específica a essa ciência (categoria), nesse caso o Espaço. Portanto, cabe aqui uma premissa para que possamos dar continuidade a análise que nos propusemos, que é explicitar o conceito de Espaço ao qual nos reportamos. Dessa maneira, emprestaremos a definição de Espaço de Santos, para o qual,

O espaço seria um conjunto de objetos e de relações que se realizam sobre estes objetos; não entre estes especificamente, mas para as quais eles servem de intermediários. Os objetos ajudam a concretizar uma série de relações. 0 espaço é resultado da ação dos homens sobre o próprio espaço, intermediados pelos objetos, naturais e artificiais (SANTOS, 1988, p.25).

A construção de nossa análise tenderá a pensar o que seriam esse conjunto de objetos e as relações que eles estabelecem tendo o urbano das cidades já citadas, como espaço onde encontramos objetos que simbolizam o atual estágio de desenvolvimento da agricultura de commodities (agronegócio) e como essa lógica produtiva acaba por reorganizar o espaço para o funcionamento desse modelo de produção. Para tal, nos reportaremos a Santos quando diz, "o importante é realçar a inseparabilidade entre ação e objeto, para afirmar, como estamos fazendo, que o tema central da geografia não é separadamente os objetos, nem as ações, mas objetos e ações tomados em conjunto" 
(SANTOS, 2006, p.60).

No caso especifico dessa análise (processo urbano), fica explícito que nos últimos 15 anos o espaço do cerrado amapaense, bem como as cidades de Santana e Porto Grande ${ }^{1}$ a que nos propusemos a analisar, vem sofrendo uma reorganização, com o surgimento de novos objetos que antes não compunham a paisagem dessas cidades ou que agora ganham nova importância, já que são incorporados a um sistema de relações que possibilitam a existência de tal modelo produtivo, mesmo que em alguns casos os fluxos estabelecidos não sejam explícitos a um observador menos curioso.

Os elementos fixos, fixados em cada lugar, permitem ações que modificam o próprio lugar, fluxos novos ou renovados que recriam as condições ambientais e as condições sociais, e redefinem cada lugar. Os fluxos são um resultado direto ou indireto das ações e atravessam ou se instalam nos fixos, modificando a sua significação e o seu valor, ao mesmo tempo em que, também, se modificam.

Fixos e fluxos juntos, interagindo, expressam a realidade geográfica e é desse modo que conjuntamente aparecem como um objeto possível para a geografia. Foi assim em todos os tempos, só que hoje os fixos são cada vez mais artificiais e mais fixados ao solo; os fluxos são cada vez mais diversos, mais amplos, mais numerosos, mais rápidos.

O espaço é hoje um sistema de objetos cada vez mais artificiais, povoado por sistemas de ações igualmente imbuídos de artificialidade, e cada vez mais tendentes a fins estranhos ao lugar e a seus habitantes (SANTOS, 2006, p.38- 39).

É importante frisar que esses objetos são construídos, fato que acaba por revelar o caráter político das ações dos indivíduos ligados por esse tipo de produção ou ainda atingido diretamente por ele.

A partir do reconhecimento dos objetos na paisagem, e no espaço, somos alertados para as relações que existem entre os lugares. Essas relações são respostas ao processo produtivo no sentido largo, incluindo desde a produção de mercadorias à produção simbólica (SANTOS, 2006, p. 45).

Os objetos que surgem ou são ressignificados na paisagem urbana dos municípios pesquisados, e vão desde a infraestrutura para dar fluidez a produção instalada no cerrado amapaense, como por exemplo a rodovia BR156, que dá acesso as áreas produtoras de commodities no estado do Amapá, o Porto da cidade de Santana, que liga a produção de commodities do Amapá a uma rede de transporte, instituições, como por exemplo a Embrapa, secretarias de Estado, Institutos e Universidades que subsidiam pesquisas de viabilidade e maior produtividade, além de maneiras de arrecadar impostos advindos dessa produção.

Os objetos que interessam à Geografia não são apenas objetos moveis, mas também imóveis, tal uma cidade, uma barragem, uma estrada de rodagem, um porto, uma floresta, uma plantação, um lago, uma montanha. Tudo isso são objetos geográficos. Esses objetos geográficos são do domínio tanto do que se chama a Geografia Física como do domínio do que se chama a Geografia Humana e através da história desses objetos, isto é, da forma como foram produzidos e mudam, essa Geografia Física e essa Geografia Humana se encontram (SANTOS, 2006, p. 46).

O Estado, aparece como o principal articulador e financiador da construção desses sistemas de objetos e ações, que a princípio planeja formas de induzir a instalação de empreendimentos ligados ao agronegócio. De acordo com Sá (1986, p.13), "o Estado, a sua organização, as funções que exerce, o modo como as executa, os fins que prossegue e os métodos que adota, estão no centro da luta política

\footnotetext{
1 Municípios localizados no eixo de circulação da produção da soja, a BR 156, que vai do Sul (Santana) e ao Norte da cidade de Macapá (Porto Grande).
} 
e do debate ideológico da nossa época.

Há ainda o setor privado, composto na sua maioria por empresas transnacionais, que acabam por aparecer na paisagem através da venda produtos como máquinas, implementos e químicos. Há ainda uma pequena parcela do setor privado ligado a prestação de serviços, como por exemplo, hotéis, restaurantes e algum tipo de manutenção que não requer mão de obra especializada.

Impõe-se distinguir entre atores que decidem e os outros. Um decididor e aquele que pode escolher o que vai ser difundido e, muito mais, aquele capaz de escolher a ação que, nesse sentido, se vai realizar. Essa ideia é desenvolvida por J. Masini (1988, pp. 112 -113) que inclui, entre os grandes decididores, os governos, as empresas multinacionais, as organizações internacionais, as grandes agências de notícias, os chefes religiosos... A escolha do homem comum, em muitas das ações que empreende, é limitada. Frequentemente, o ator é apenas o veículo da ação, e não o seu verdadeiro motor. Mas é sempre por sua corporeidade que o homem participa do processo de ação (SANTOS, 2006, p. 51).

Diante de tal afirmação, podemos pensar em como se dá a representação de tal corporeidade que participa simbolicamente da construção do processo, porém como diz Santos, não é força motriz do processo, mas engrenagem específica de racionalização do espaço que modifica ou ressignifica as ações do e no Espaço.

Podemos pensar nos representantes das instituições acima elencadas como a corporificação do atual estágio de produção do agronegócio no urbano das cidades pesquisadas, no qual o binômio, Estado e Iniciativa Privada possuem atores decididores capazes de organizar a produção do espaço de forma a privilegiar de forma seletiva pessoas ou grupo de pessoas a fim de manter uma cadeia de dominação da maioria da sociedade. Esse poder interventor é o que Bourdieu (1998 p. 7) entende por poder simbólico que "é, com efeito, esse poder invisível o qual só pode ser exercido com a cumplicidade daqueles que não querem saber que lhe estão sujeitos ou que o exercem".

Ao organizar a produção do/no espaço, são criadas novas formas de exclusão, e explicitadas outras que podem inclusive serem anteriores a esse novo modelo produtivo. Isso acontece porque mesmo anteriormente a chegada do agronegócio ao Amapá, a organização social já acontecia tendo por base o sistema de produção capitalista, ou seja, a contradição, que é essência desse modelo, já havia criado formas de exclusão sob o modelo produtivo hegemônico.

A ideia aqui é pensar essa nova forma de exclusão advinda da influência do agronegócio no espaço urbano pesquisado, como novas fronteiras, para isso nos utilizaremos do conceito de Martins (1997, p.151):

O desencontro na fronteira é o desencontro de temporalidades históricas, pois cada um desses grupos está situado diversamente no tempo da história. Por isso, a fronteira tem sido cenário de encontros extremamente similares aos de Colombo com os índios da América: as narrativas das testemunhas de hoje, cinco séculos depois, nos falam das mesmas recíprocas visões e concepções do outro.

Martins (1997, p 150), aponta ainda o caráter singular da fronteira. Entende a fronteira enquanto o lugar do outro e de desencontro, essencialmente o lugar da alteridade. Nas palavras do autor:

[...] À primeira vista é o lugar do encontro dos que por diferentes razões são diferentes entre si, como os índios de um lado, e os civilizados de outro; como os grandes proprietários de terra, de um lado, e os camponeses pobres, de outro. Mas o conflito faz com que a fronteira seja essencialmente, a um só tempo, um lugar de descoberta do outro e 
de desencontro.

O urbano como fronteira tende a aparecer como facetas ainda mais perversas de exclusão uma vez que já se tratam da separação do trabalhador ao modo de produção, portanto podemos afirmar ainda que o urbano se configura enquanto uma multiescalaridade de exclusões, mesmo que o próprio sistema capitalista de produção crie necessariamente (re) existências nas formas mais variadas de luta pela vida.

Como continuidade a essa discussão teórica, passaremos a utilizar de linguagens visuais para enriquecer e demonstrar como se materializam as novas fronteiras no espaço urbano que compreende as cidades de Macapá, Santana e Porto Grande.

\section{Ocupação do cerrado pelo agronegócio e suas implicações no espaço urbano de Macapá}

A área do cerrado ocupa 6,9\% do território amapaense (Figura 1), o qual se acessa via BR 156.

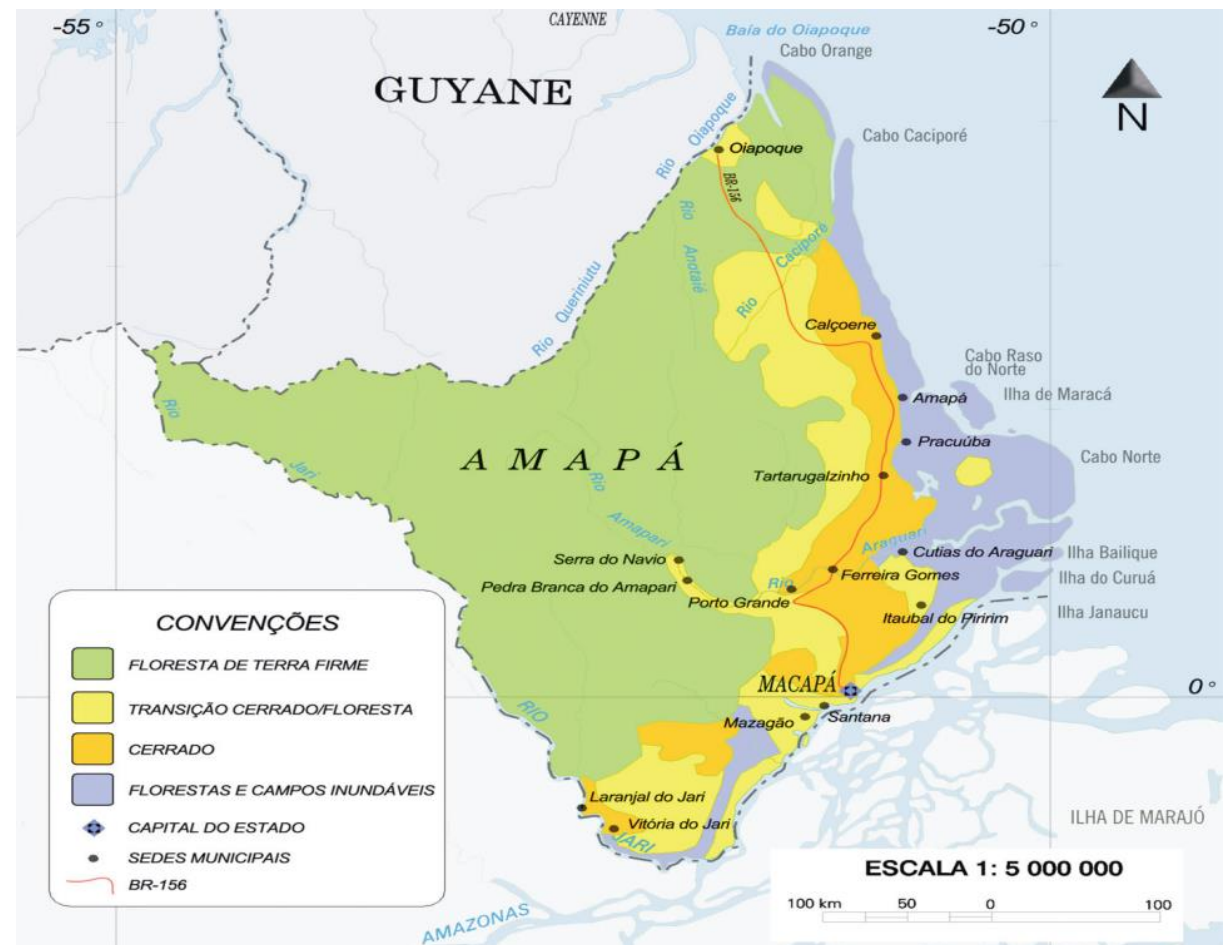

Figura 1. Principais domínios florísticos do Estado do Amapá

Fonte: IBGE (2013), adaptada por Alves e Castro (2014).

A Associação dos Produtores de Soja do Amapá - APROSOJA/AP informou que do total da soja produzida no Amapá, $80 \%$ vai para o mercado europeu e 20\% para a China. Em 2016, segundo o IBGE, a produção de soja no Amapá foi de 42 mil toneladas, enquanto a previsão para o fechamento do corrente ano (2017) é de 49 mil toneladas, aumentando em 17\% a produtividade. Quando analisamos os dados fornecidos, podemos ter dimensão do crescimento da utilização das terras do cerrado pelo agronegócio (Tabela 1). 
Tabela 1. Projeção de áreas plantada com agricultura de grãos para o Estado do Amapá

\begin{tabular}{|l|ccccc|}
\hline Cadeia produtiva & 2012 & 2013 & 2020 & 2025 & 2030 \\
\hline Soja (ha) & 1.714 & 6.465 & 30.000 & 50.000 & 120.000 \\
\hline Milho (ha) & 561 & 2.000 & 15.000 & 25.000 & 50.000 \\
\hline Arroz (ha) & 478 & 1.000 & 4.000 & 8.000 & 15.000 \\
Feijão-caupi (ha) & 100 & 350 & 5.500 & 9.000 & 20.000 \\
\hline Total & 2.853 & 9.815 & 54.500 & 92.000 & 205.000 \\
\hline
\end{tabular}

Fonte: Alves e Castro (2014).

Concomitantemente ao crescimento da área ocupada pelo agronegócio no cerrado amapaense, observamos o crescimento populacional (Figura 2) no estado do Amapá, principalmente na região onde estão localizadas as cidades elencadas nesta pesquisa.

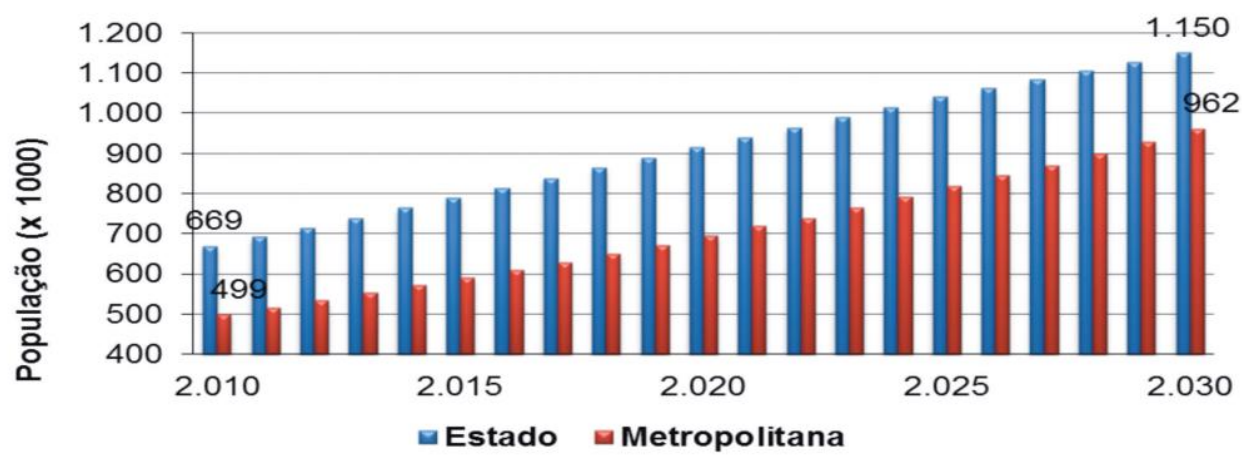

Figura 2. Projeção do crescimento populacional (x 1000) do Estado do Amapá e da região metropolitana Macapá e Santana, até o ano de 2030 Fonte: Alves e Castro (2014).

O estado, como destacamos, é um dos principais agentes decididores dos rumos políticos e econômicos a serem trilhados aparece na paisagem urbana na forma de ações, como as conduzidas por um de seus aparelhos simbólicos, nesse caso, a Embrapa e seus estudos de viabilidade encomendados e pagos com dinheiro público e que são acessíveis a uma pequena parcela específica da população que detém capital suficiente para implementar todas as premissas ligadas e esse modelo produtivo.

Em recente estudo realizado pela Embrapa Amapá usando como metodologia a matriz FOFA2, indicam as forças internas que podem subsidiar o aumento da produção da soja, são: terras disponíveis para integrar o processo produtivo, baixo risco de passivo ambiental, baixo risco de passivo agrário, entre outras. Estudo que contraria ao afirmado pela Pastoral da Terra do Amapá, ao denunciar o aumento dos conflitos pela terra no Estado do Amapá.

Na cidade de Porto Grande é observado o surgimento de cursos de formação técnica, ofertados pelo Instituto Federal do Amapá, com o intuito de formar mão de obra qualificada para suprir as necessidades desse mercado (Figura 3).

2 Instrumento de avaliação de desempenho utilizado no campo do planejamento, analisa os pontos fortes (Fortalezas e Oportunidades) e as fragilidades (Fraquezas e Ameaças), e que permite a avaliação de sua estrutura. 


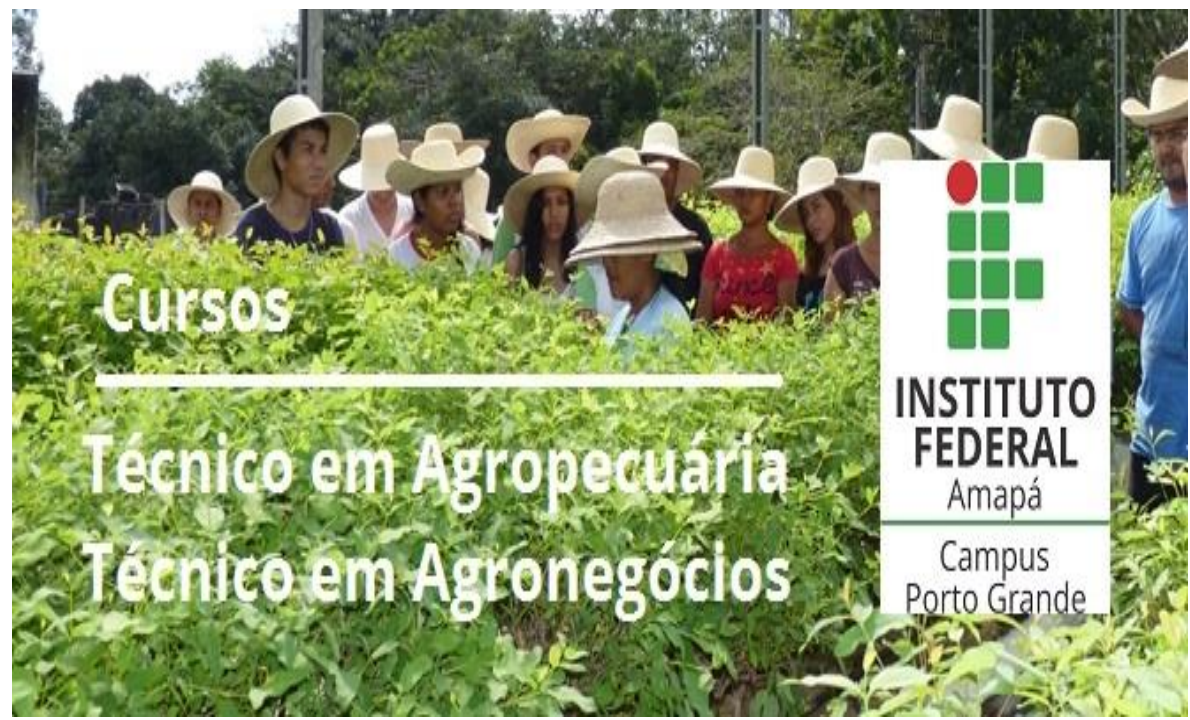

Figura 3: Divulgação de cursos no Instituto Federal do Amapá Campus Porto Grande

Fonte:http://www.diariodoamapa.com.br/2016/01/29/agropecuaria-eagronegocios-curso-oferece-47-vagas-para-porto-grande/

Na cidade de Santana, o porto vem passando por uma série de obras para tornar possível a armazenagem e o carregamento de grãos, já que historicamente esse porto nunca trabalhou com esse tipo específico de carga (Figura 4). 0 porto de Santana é considerado estratégico pela proximidade aos mercados consumidores dos produtos do agronegócio.

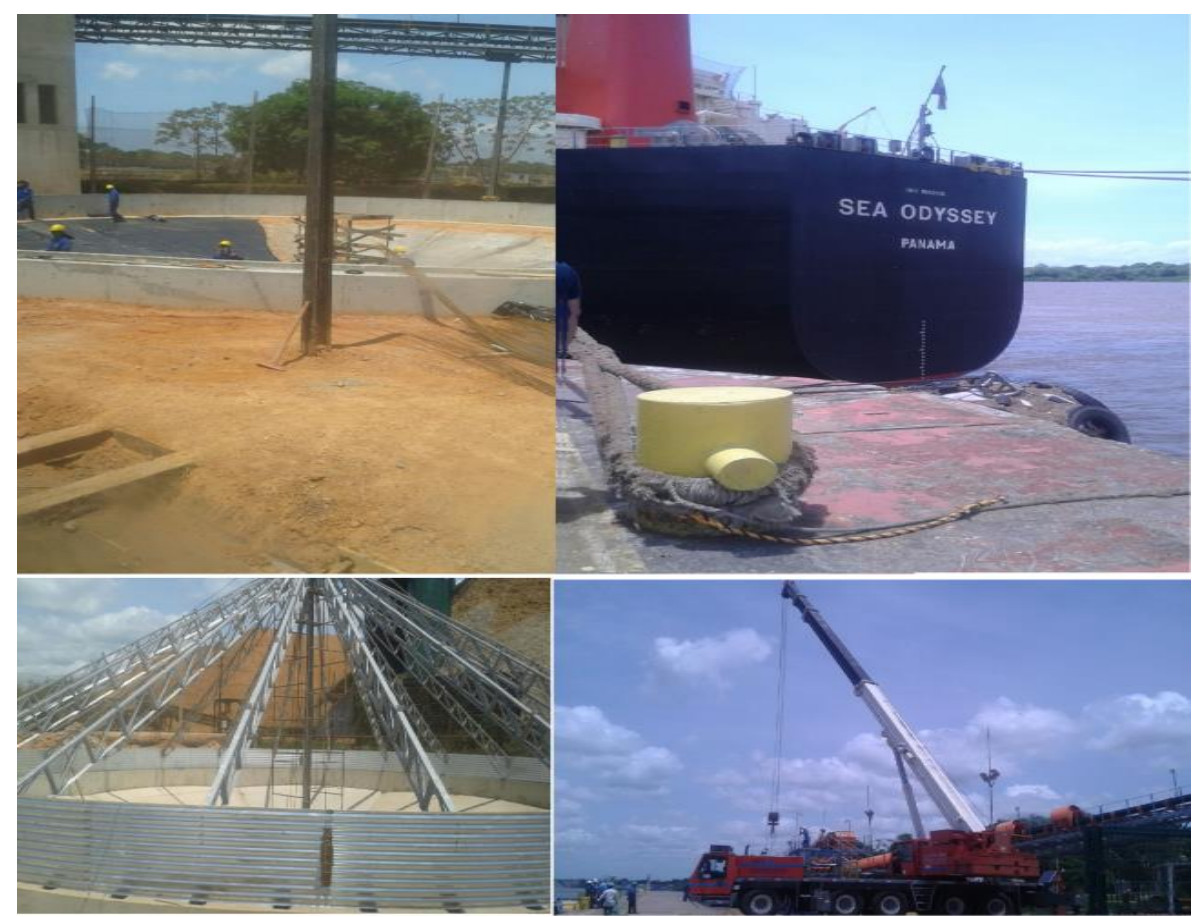

Figura 4: Obras para armazenamento e transporte de grãos em Santana

Fonte: Autores do trabalho 


\section{Considerações Finais}

Apesar do processo de ocupação do cerrado amapaense pelo agronegócio ser recente, é possível constatar, como demonstrado nesse esforço inicial, uma série de ações por parte dos chamados agentes decididores (capital privado e Estado), no intuito de dar fluidez a produção de commodities. Essa produção e transformação no espaço urbano das cidades amapaenses pesquisadas nesse trabalho, possuem materialidades ainda timidamente percebidas, ao contrário do campo político em que essas ações já são colocadas como as promotoras do desenvolvimento do Estado do Amapá. Esse processo está acontecendo sem o amplo debate com a sociedade quanto aos problemas que esse tipo de empreendimento causa, e se tratando das cidades mencionadas, cabe-nos pensar as consequências do aumento migratório para essas áreas urbanas, que possuem certa deficiência estrutural, que consiga garantir condições básicas de cidadania.

\section{Referências}

ALVES, Luís W. R.; CASTRO, Gustavo S. A. Produção de Grãos: Potencial para Geração de Riqueza no Cerrado do Estado do Amapá. Macapá: EMBRAPA, 2014.

BOURDIEU, Pierre. O poder simbólico. 2ª ed. Rio de Janeiro: Bertrand Brasil, 1998.

CARLOS, Ana Fani A. O lugar no/do mundo. São Paulo: Labur Edições, 2007.

INSTITUTO BRASILEIRO DE GEOGRAFIA E ESTATÍSTICA. Censo Demográfico 2010. Disponível em:

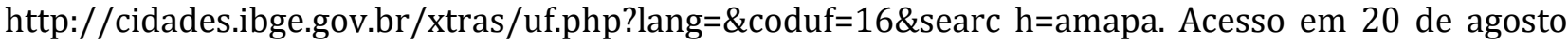
de 2016.

INSTITUTO BRASILEIRO DE GEOGRAFIA E ESTATÍSTICA. Estimativas populacionais para os municípios $e$ para as Unidades $d a$ Federação brasileiros. Disponível em <http://ibge.gov.br/home/estatistica/populacao/ estimativa2016/default.shtm>. Acesso em 03 de setembro de 2016 .

LEFEBVRE, Henri. A produção do espaço. Trad. Doralice Barros Pereira e Sérgio Martins (do original: La production de l'espace. 4ae éd. Paris: Éditions Anthropos, 2000). Primeira versão: início - fev.2006

MARTINS, José de S. Fronteira: a degradação do Outro nos confins do humano. São Paulo: Hucitec, 1997. $213 \mathrm{p}$.

SÁ, Luís. Introdução a teoria do Estado. Lisboa: Editora Caminho, 1986.

SANTOS, Milton. Espaço e Método. São Paulo: Nobel, 1985.

SANTOS, Milton. Metamorfoses do espaço habitado: fundamentos teórico e metodológico da geografia. Hucitec.São Paulo 1988.

Técnica Espaço Tempo: Globalização e meio técnico científico-informacional. São Paulo: Hucitec,1994

A Natureza do espaço: Técnica e Tempo, Razão e Emoção. 4. ed. 2. reimpr. - São Paulo: Editora da Universidade de São Paulo, 2006.

TAVARES, Ana Paula C. A evolução urbana de uma cidade no meio do mundo. Revista Nacional de Gerenciamento de Cidades, v. 01, n. 04, 2013, pp. 36-41. 